\title{
Dietary diversity and associated factors among pregnant women attending antenatal care at public health facilities in Bale Zone, Southeast Ethiopia
}

This article was published in the following Dove Press journal: Nutrition and Dietary Supplements

\author{
Sintayehu Hailu' \\ Bedasa Woldemichael ${ }^{2}$ \\ 'Department of Public Health, School of \\ Health Sciences, Goba Referral Hospital, \\ Madda Walabu University, Bale-Goba, \\ Ethiopia; ${ }^{2}$ Department of Nursing, School \\ of Health Sciences, Goba Referral \\ Hospital, Madda Walabu University, Bale- \\ Goba, Ethiopia
}

Background: Dietary diversity is a proxy indicator of nutrient adequacy. However, little is documented on dietary diversity among pregnant women in Ethiopia in general and specifically in the study area. This study assessed dietary diversity and associated factors among pregnant women attending antenatal care in public health facilities in Bale Zone, Southeast Ethiopia.

Methods: An institution-based cross-sectional study was conducted in Bale Zone from January to March 2017. The sample size was determined using a single population proportion formula. Data were collected by pretested structured interviewer-administered questionnaires from a total of 413 pregnant women who were identified through systematic random sampling. The sample was drawn proportionally from selected public health facilities based on the client load. Dietary diversity was computed from information about the nine food groups obtained using a 24-hour dietary recall method. Statistical analysis was done using bivariate and multivariate logistic regression with the $P$-value $<0.05$ at $95 \%$ confidence interval considered as statistically significant.

Results: The mean age of the pregnant women was 26.93 with standard deviation \pm 6.12 years. About $55.2 \%$ of the pregnant women had inadequate dietary diversity. Getting information from a health professional [AOR $=5.26,95 \% \mathrm{CI}(1.60,17.36)]$, being an urban dweller $[\mathrm{AOR}=8.95,95 \% \mathrm{CI}(4.42,18.16)]$, having a protected water source [AOR $=11.16,95 \% \mathrm{CI}(4.74,26.27)]$, having a latrine $[\mathrm{AOR}=8.21,95 \% \mathrm{CI}(4.01,16.80)]$, having a home garden $[\mathrm{AOR}=4.26,95 \% \mathrm{CI}(2.08,8.70)]$, having a bank account $[\mathrm{AOR}=12.25$, $95 \% \mathrm{CI}(6.01,24.97)]$ and having use of a mobile phone $[\mathrm{AOR}=3.82,95 \% \mathrm{CI}(1.92,7.62)]$ were significantly associated with dietary diversity.

Conclusion: In this community, the prevalence of inadequate dietary diversity is high. Variables which indicate a better living condition such as having a protected source of water, having a latrine, having a home garden, being an urban dweller, having a bank account and having use of a mobile phone were independent predictors of dietary diversity. Therefore, attention should be paid to improve to better living conditions of pregnant women by addressing determinate variables through community awareness.

Keywords: dietary diversity, pregnant women, antenatal care, Ethiopia

\section{Background}

Correspondence: Sintayehu Hailu Department of Public Health, School of Health Sciences, Goba Referral Hospital, Madda Walabu University, P. O. Box: 302,

Bale-Goba, Ethiopia

Tel +251933853458

Email sinteyehu198I@gmail.com
Nutrition has a significant impact on maternal and child health as it is the basis for long-term health outcomes. ${ }^{1}$ Good nutrition during pregnancy is a fundamental determinant for growth and development of infants and better nutritional status of mothers. ${ }^{2,3}$ However, pregnant women are more likely than others to suffer from 
nutritional deficiency owing to physiological vulnerability, as well as lack of education, socio-cultural traditions, and household work patterns. ${ }^{1-3}$ To minimize this burden, pregnant women need to eat about 350 additional kilocalories above the usual daily food intake. ${ }^{2}$ But, this is not easy for pregnant women who are living in low income countries due to intake of monotonous, cereal-based diets, inadequate vegetables and fruits as well as animal source foods. ${ }^{4-6}$ Pregnant mothers who were exposed to malnutrition during pregnancy and childbirth, and their children are exposed to unexpected developmental pathways both physically and mentally. As it has been described by different researchers, pregnant women who have a poor nutritional status are also at risk of an adverse birth outcome such as intrauterine growth, obstructed labor, having a baby with a low birth weight, or death due to postpartum hemorrhage. 7 Based on the United Nations Children's Fund (UNICEF) conceptual framework of malnutrition, the immediate causes of maternal malnutrition are inadequate dietary intake and diseases. ${ }^{8}$ Inadequate dietary intake is due to insufficient food availability at the household associated with development of under nutrition, especially during pregnancy which is associated with failure for optimal health. ${ }^{9}$ Dietary diversity is intake of a variety of foods across food groups which enables the safeguarding of an adequate intake of essential nutrients that can promote health, physical and mental development. ${ }^{10}$ It is an indicator for measuring dietary adequacy of pregnant women. ${ }^{11-14}$ The diet which is consumed by pregnant women reflects not only their own intake, but also the diets of their families. ${ }^{15}$ In short, a pregnant woman with higher dietary diversity ensures the adequacy of dietary diversity for their children and families. Inadequate dietary diversity at individual, household and community levels, or any combination of these, may be predisposing factors to poor nutrition status which perpetuates an intergenerational cycle of malnutrition. ${ }^{16}$ Thus, to guarantee maternal dietary diversity at an acceptable level is very important in confronting under nutrition. Around 870 million people are estimated to be underweight around the world. Out of these, 852 million live in developing countries. ${ }^{15}$ More than 3.5 million women and children age under five in developing countries die each year due to the underlying cause of under nutrition. ${ }^{16}$ In Africa alone, $20 \%$ of women are underweight. ${ }^{17-20}$ About 800 pregnant women die every day during pregnancy and childbirth and 8,000 newborn babies die within the first month of life in developing countries, representing about $98 \%$ of newborn deaths and
$99 \%$ of maternal deaths. ${ }^{16}$ According to the Federal Democratic Republic of Ethiopia National Nutrition Program report (2015), more than $90 \%$ of the children in rural Ethiopia were fed with less than four food groups out of seven food groups. ${ }^{21}$ As an international food policy research institute study demonstrated in different regions of Ethiopia more than $50 \%$ of children consumed less than two out of seven food groups. ${ }^{22}$ However, little information is documented about the dietary diversity of pregnant women in Ethiopia, specifically our study area. Therefore, this study aimed to assess dietary diversity and associated factors among pregnant women attending antenatal care at public health facilities in Bale Zone, Southeast Ethiopia.

\section{Methods}

\section{Study design, area and period}

A facility-based cross-sectional study was carried out to assess dietary diversity among pregnant women in public health facilities in Bale Zone, Southeast Ethiopia in 2017. The Zone is found in Oromia Regional State $430 \mathrm{~km}$ away from Addis Ababa, the capital city of Ethiopia. The topography of the zone is composed of $14.92 \%$ highland, $21.53 \%$ midland and $63.55 \%$ lowland with an altitude range of $300-4,377 \mathrm{~m}$ and annual rainfall of $900-1,400 \mathrm{~mm}$. The total population is $1,857,383$ including 896,265 females. $^{23}$ The main sources of food in the zone include: cereal crops, fruit, vegetables, and animal products. The estimated number of pregnant women in the zone was $65,023 .^{24}$ The study period was from January-March, 2017.

\section{Population, sample size determination and sampling techniques}

Pregnant women who visited the public health facilities during the study period and selected by a systematic random sampling technique were considered as the study population, drawn from the source population of all pregnant women who attended antenatal care at public health facilities in Bale Zone. To be included in the study, the women had to be resident in Bale Zone for at least 6 months. Pregnant women who were seriously ill and/or had difficulty communicating were excluded. The required sample size was determined using a single population proportion formula with the following assumptions: $50 \%$ of proportion, at $95 \%$ of confidence interval and 0.05 marginal errors with an additional $10 \%$ added to account for non-response. The final sample size was 422 . The total pregnant women 
who attended antenatal care in a public health facility in the previous 3 months at the selected public health facilities were determined. Based on a comparison of the client load of the health facilities, the sample of the study was allocated proportionally. Then every 3rd pregnant woman visiting the public health facilities was interviewed.

\section{Data collection procedures}

Data on potential determinants of dietary diversity were collected using structured and pretested questionnaires through interviews. The validity of the questionnaire was checked against the conceptual framework of the study. The questionnaire was administered in the local language, Afan Oromo. ${ }^{3,16}$ The questionnaire had three main components: socio-demographic characteristics; feeding pattern, and obstetric history. Parts of the questionnaire on dietary diversity were adopted from the Food and Agriculture Organization (FAO) of the United Nations guidelines for measuring individual dietary diversity. ${ }^{25}$ Locally available foods were also considered. The questionnaire was first prepared in English and then translated to Afan Oromo and translated back to English to observe its consistency. The translated Afan Oromo version was pretested prior to the actual survey and modifications were made accordingly. Five data collectors and one supervisor were recruited. Training was provided by the principal investigator to ensure consensus and understanding of what was intended to be measured by each question in the questionnaire and the data collection process was monitored daily by the supervisor and principal investigator.

The dietary diversity (DD) level was assessed using a 24-hour recall method. Respondents were asked whether they had taken any food from nine pre-defined groups (ie cereals, dark green leafy vegetables, flesh meats, eggs, fish and seafood, legumes, nuts and seeds, milk and milk products, and oils and fats). Pregnant women who consumed less than four food groups were deemed as low dietary diversity while those who consumed four or more food groups were considered as having adequate dietary diversity. ${ }^{2}$ Mid upper arm circumference (MUAC) was measured halfway between the olecranon process and acromion process using non stretchable tape to the nearest $0.1 \mathrm{~cm}$ to determine the nutritional status of the participants. Undernutrition was defined as MUAC less than $21 \mathrm{~cm}$ while normal nutritional status was considered to be $21 \mathrm{~cm}$ or more.

\section{Data processing and analysis}

Data were cleaned and entered into a database using EpiInfo version 7 then transferred to Statistical Package for the Social Science (SPSS) version 21 (IBM Corporation, Armonk, NY, USA) for analysis. Dietary diversity was dichotomized as a category into Adequate and Inadequate. Descriptive analysis was done to determine means, frequencies and percentage distributions for the variables. A bivariate analysis was applied to see the crude effect of each independent variable on adequate dietary diversity. Variables with $P$-values of $<0.2$ were entered into the multivariable logistic regression analysis. A stepwise backward elimination procedure was used in the multiple logistic regressions. The association between the dependent and the independent variables was measured using odds ratio (OR) with 95\% Confidence Interval (CI). A $P$-value of $<0.05$ was considered as statistically significant.

\section{Ethics approval and consent to participate} Ethical clearance was approved by Madda Walabu University Research and Publication Ethical Review Committee. This committee confirmed that obtaining verbal consent from the study participants was sufficient for this study according to guideline Document 0006 of Research Ethics Policy and Procedures of Madda Walabu University in 2012. A letter of introduction supporting the research was obtained from the University Research Directorate and directed to the Bale Zone Health Office. After a brief explanation about the purpose of the study to the Zonal Health office, an official letter was written to health facilities. Data were subsequently collected after getting consent from study participants through informing them about the purpose, benefit, risk, the confidentiality of the information collected, and the voluntary nature of participation in the study.

\section{Results}

Socio-demographic characteristics of pregnant women attending antenatal care public health facilities, in Bale Zone, Southeast Ethiopia, $2017(n=4 / 3)$

A total of 422 pregnant women were included in this study with a response rate of $97.9 \%$. More than $65 \%$ of pregnant women were less than 30 years of age. About three fourths 
of the pregnant women were Oromo in ethnicity $(75.8 \%)$ and more than 50\% Muslim in religion (55.9\%). More than half of the participants were housewives (54\%) and had no formal education (40.2\%). Nearly two-thirds of the pregnant women were rural residents (60.5\%) and had more than five children $(58.8 \%)$. About one-third of the participants had a monthly income less than 500 Ethiopian birr (Table 1).

Table I Sociodemographic characteristics of pregnant women attending antenatal care at public health facilities in Bale Zone, Southeast Ethiopia, $2017(n=413)$

\begin{tabular}{|c|c|c|c|}
\hline \multicolumn{2}{|l|}{ Variables } & \multirow{3}{*}{$\begin{array}{l}\text { Frequency } \\
283 \\
130\end{array}$} & \multirow{3}{*}{$\begin{array}{l}\text { Percentage } \\
\text { (\%) } \\
68.5 \\
31.5\end{array}$} \\
\hline Age & $<30$ & & \\
\hline & $\geq 30$ & & \\
\hline \multirow{2}{*}{$\begin{array}{l}\text { Place of } \\
\text { residence }\end{array}$} & Rural & 250 & 60.5 \\
\hline & Urban & 163 & 39.5 \\
\hline \multirow[t]{3}{*}{ Marital status } & Married & 398 & 96.4 \\
\hline & Divorced & 11 & 2.7 \\
\hline & Widowed & 4 & 1.0 \\
\hline \multirow[t]{3}{*}{ Religion } & Orthodox & 147 & 35.6 \\
\hline & Muslim & 231 & 55.9 \\
\hline & Protestant & 35 & 8.5 \\
\hline \multirow[t]{3}{*}{ Ethnicity } & Oromo & 313 & 75.8 \\
\hline & Amhara & 63 & 15.3 \\
\hline & Tigre & 37 & 9.0 \\
\hline \multirow[t]{3}{*}{$\begin{array}{l}\text { Educational } \\
\text { status }\end{array}$} & $\begin{array}{l}\text { No formal } \\
\text { education }\end{array}$ & 166 & 40.2 \\
\hline & Primary & 143 & 34.6 \\
\hline & $\begin{array}{l}\text { Secondary and } \\
\text { above }\end{array}$ & 104 & 25.2 \\
\hline \multirow{4}{*}{$\begin{array}{l}\text { Occupational } \\
\text { status }\end{array}$} & Housewife & 223 & 54.0 \\
\hline & $\begin{array}{l}\text { Government } \\
\text { employee }\end{array}$ & 130 & 31.5 \\
\hline & Merchant & 48 & 11.6 \\
\hline & Labourer & 12 & 2.9 \\
\hline \multirow[t]{2}{*}{ Family size } & $\leq 5$ & 170 & 41.2 \\
\hline & $>5$ & 243 & 58.8 \\
\hline \multirow[t]{5}{*}{ Income } & $<500$ ETB* & 123 & 29.8 \\
\hline & $500-1,500$ & 139 & 33.7 \\
\hline & ETB & & \\
\hline & $>1,500$ ETB & 49 & 11.9 \\
\hline & Unknown & 102 & 24.7 \\
\hline
\end{tabular}

Note: *Ethiopian Birr.
Source of information, feeding pattern and nutritional status among pregnant women attending antenatal care public health facilities in Bale Zone, Southeast Ethiopia, $2017(n=413)$

More than one-third of the pregnant women were getting health information from the radio (39.9\%), whereas only $12.5 \%$ of them were get health information from neighbors (Figure 1). More than half (55.2\%) the pregnant women had inadequate diversity. Almost half $(47 \%)$ the pregnant women were undernourished. A majority $(77.2 \%)$ of participants reported that they consumed meals twice per day. However, $21 \%$ of pregnant women reported eating additional food during pregnancy (Table 2). Regarding the food groups consumed by the pregnant women in the previous 24 hours, about $87.9 \%$ consumed starchy staples while $8.2 \%$ reported consuming fish and fish products (Figure 2).

\section{Factors associated with dietary diversity}

The bivariate logistic regression analysis shows that being rural, family size, source of information, source of water, having a latrine, having a home garden and having a mobile phone were the factors associated with adequate dietary diversity among the pregnant women. However, in the multivariable logistic regression analysis, a few variables such as source of information from TV and radio, using protective water, having a latrine, having a home garden and having a mobile phone were factors associated with adequate dietary diversity (Table 3 ).

\section{Discussion}

In the current study, about (54.5\%) of the pregnant women had consumed $<4$ food groups (low dietary diversity), whereas $(44.8 \%)$ had consumed $\geq$ four food groups (adequate dietary diversity) in the last 24 hours. This prevalence was lower than the study done in Laikipia, Kenya $(61 \%),{ }^{26}$ and higher than studies done in South Africa $(25 \%)^{5}$ and Gondar, Ethiopia (16.2\%). ${ }^{27}$ This discrepancy might be due to difference in study period, geographical area, and/or socio-cultural factors.

In this study, nearly $88.9 \%$ and $75 \%$ of the pregnant women had consumed cereal, and legumes respectively in the previous 24 hours and only $8.2 \%$ of them had consumed fish or fish products in the previous 24 hours. This finding is almost consistent with the finding of other studies conducted in Laikipia, Kenya, ${ }^{26}$ and Southern Ethiopia. ${ }^{27}$ Furthermore, many studies in developing countries have documented that 


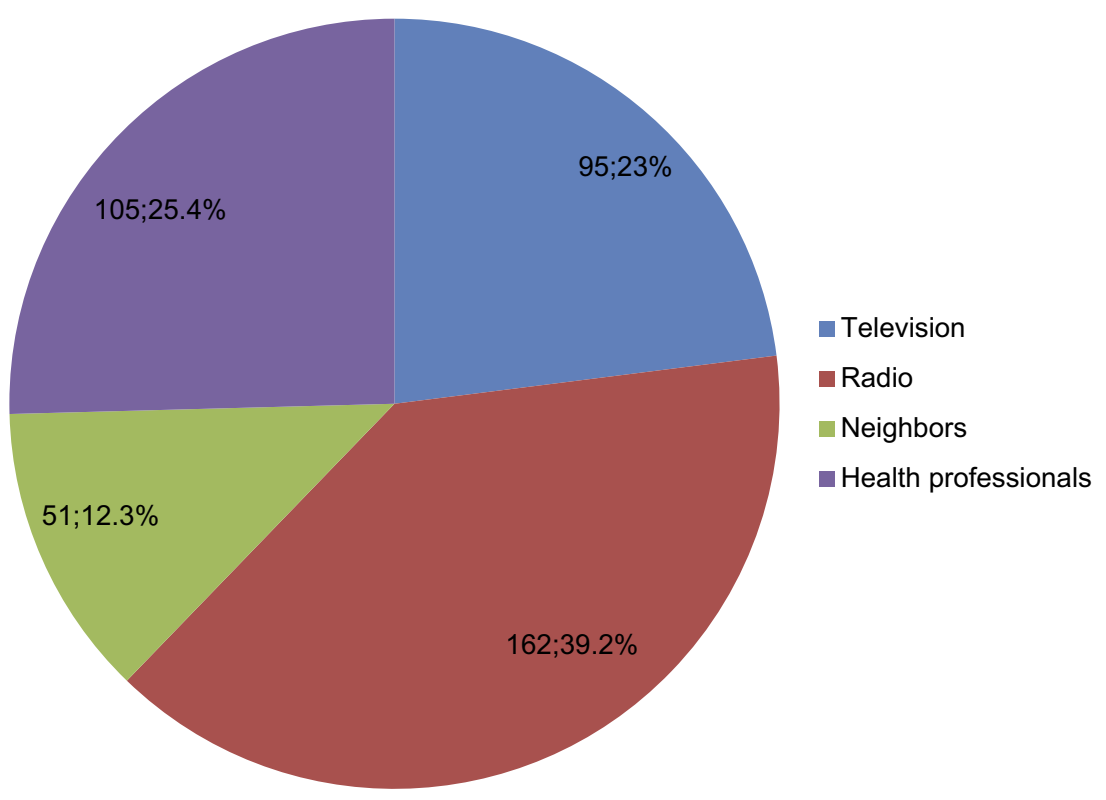

Figure I Sources of information for dietary diversity among pregnant women attending antenatal care in public health facilities in Bale Zone, Southeast Ethiopia, 2017.

Table 2 Dietary diversity and nutritional status among pregnant women attending antenatal care in public health facilities in Bale Zone, Southeast Ethiopia, $2017(n=413)$

\begin{tabular}{|c|c|c|c|}
\hline \multicolumn{2}{|l|}{ Variables } & \multirow{2}{*}{$\begin{array}{l}\text { Frequency } \\
228 \\
185\end{array}$} & \multirow{2}{*}{$\begin{array}{l}\text { Percentage } \\
55.2 \\
44.8\end{array}$} \\
\hline $\begin{array}{l}\text { Dietary } \\
\text { diversity }\end{array}$ & $\begin{array}{l}\text { Inadequate } \\
\text { Adequate }\end{array}$ & & \\
\hline Trimester & $\begin{array}{l}\text { First } \\
\text { Second } \\
\text { Third }\end{array}$ & $\begin{array}{l}170 \\
179 \\
64\end{array}$ & $\begin{array}{l}41.2 \\
43.3 \\
15.5\end{array}$ \\
\hline $\begin{array}{l}\text { Frequency of } \\
\text { dietary intake }\end{array}$ & $\begin{array}{l}\text { Twice per day } \\
\text { Three times } \\
\text { a day }\end{array}$ & $\begin{array}{l}319 \\
104\end{array}$ & $\begin{array}{l}77.2 \\
32.8\end{array}$ \\
\hline MUAC & $\begin{array}{l}<21 \mathrm{~cm} \\
\geq 21 \mathrm{~cm}\end{array}$ & $\begin{array}{l}194 \\
219\end{array}$ & $\begin{array}{l}47 \\
53\end{array}$ \\
\hline $\begin{array}{l}\text { Additional } \\
\text { diet during } \\
\text { pregnancy }\end{array}$ & $\begin{array}{l}\text { Yes } \\
\text { No }\end{array}$ & $\begin{array}{l}87 \\
326\end{array}$ & $\begin{array}{l}21 \\
79\end{array}$ \\
\hline
\end{tabular}

Abbreviation: MUAC, mid-upper arm circumference.

their dietary sources are mainly cereal based. ${ }^{28}$ Pregnant women who were using protected water as a main source were 12.5 times more likely to have a diversified diet than those who were using unprotected water as the main source. This result is supported by different studies. ${ }^{2,18,20}$

Pregnant women who had home gardens were 2.34 times more likely to have dietary diversity when compared with those who had no home garden. This study is supported by studies conducted in Ethiopia which revealed that home gardening was strongly associated with diet diversity and with frequency of vegetable consumption. ${ }^{22,29}$ This might be due to the reason that households with gardens benefited because they are able to diversify their daily food. It has been shown elsewhere that parents with home gardens grow vegetables to obtain additional diet options that enhance the diversity of the household's food sources. ${ }^{30}$ This study has findings that agree with studies conducted in Northern Ethiopia, Nepal, and the Philippines ${ }^{13,22,30}$ that dietary diversity score was significantly higher among households with gardens. The suggested explanation for this is that gardens enable householders to diversify their daily food consumption because alternatives are easily sourced. ${ }^{31}$

Pregnant women who had mobile phones were more than four times more likely to have adequate dietary diversity than their counterparts who did not have phones. This finding is supported by studies done in South Gondar, Ethiopia. ${ }^{27,32}$ The variables such as radio and bank account also showed a strong association in the multiple logistic regression analysis. This finding is also supported by studies elsewhere. ${ }^{27,32-34}$ This might be related to personal income because dietary diversity increases as asset levels increases. ${ }^{27}$ Respondents who had a radio were two times more likely $(95 \% \mathrm{CI}: 1.2$, 3.0) to have a diversified diet compared to those who did not. This might be attributed to access to information through local broadcasting media, which broadcasts 


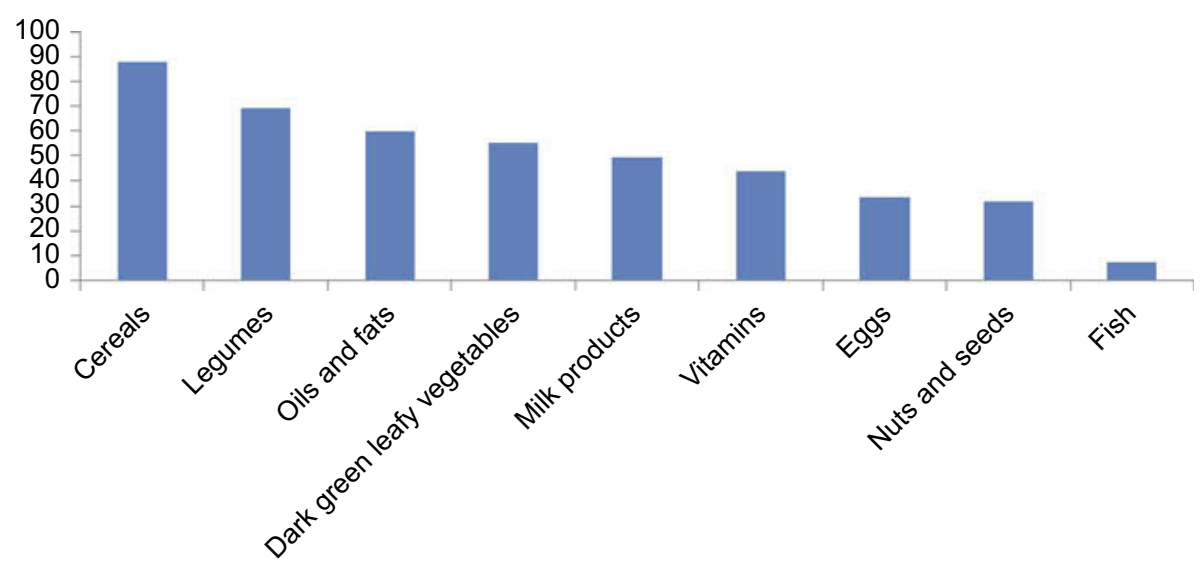

Figure 2 Food group consumptions in the last 24 hours among pregnant women attending antenatal care in public health facilities, Bale Zone, Southeast Ethiopia, 2017.

Table 3 Bivariate and multivariate logistic analysis of factors associated with dietary diversity of pregnant women attending antenatal care in public health facilities in Bale Zone South east Ethiopia, 2017 ( $n=413$ )

\begin{tabular}{|c|c|c|c|c|}
\hline \multirow[t]{2}{*}{ Variable } & \multicolumn{2}{|c|}{ Dietary diversity score } & \multirow[t]{2}{*}{ Crude OR $(95 \% \mathrm{CI})$} & \multirow[t]{2}{*}{ Adjusted OR $(95 \% \mathrm{Cl})$} \\
\hline & Inadequate, n (\%) & Adequate, n (\%) & & \\
\hline \multicolumn{5}{|l|}{ Place of residence } \\
\hline Rural & $113(45.2)$ & $137(54.8)$ & $2.91(1.91,4.42)$ & $3.72(2.22,6.20)^{*}$ \\
\hline Urban & II $15(70.6)$ & $48(29.4)$ & I & I \\
\hline \multicolumn{5}{|l|}{ Family size } \\
\hline$\leq 5$ & $84(49.4)$ & $86(50.6)$ & $1.49(1.00,2.21)$ & $\mathrm{I} .30(0.77,2.20)^{* *}$ \\
\hline$>5$ & $144(59.3)$ & $99(40.7)$ & I & I \\
\hline \multicolumn{5}{|l|}{ Source of information } \\
\hline Television & $52(54.7)$ & $43(45.3)$ & $0.58(0.32,1.02)$ & $0.4 \mathrm{I}(0.2 \mathrm{I}, 0.84)^{*}$ \\
\hline Radio & $97(59.9)$ & $65(40.1)$ & $0.47(0.28,0.78)$ & $0.45(0.24,0.85)^{*}$ \\
\hline Neighbors & $25(53.2)$ & $22(46.8)$ & $0.58(0.32,1.02)$ & $0.83(0.36,1.92)^{* *}$ \\
\hline Health professional & $14(29.2)$ & $34(70.8)$ & I & I \\
\hline Source of water & & & & \\
\hline Protected & $138(44.7)$ & I7I (55.3) & $7.97(4.35,14.60)$ & $12.49(6.01,25.96)^{*}$ \\
\hline Not protected & $90(86.5)$ & $14(13.5)$ & I & I \\
\hline \multicolumn{5}{|l|}{ Latrine present } \\
\hline Yes & $58(41.7)$ & $81(58.3)$ & $2.28(1.51,3.46)$ & $5.06(2.90,8.84)^{*}$ \\
\hline No & $170(62.0)$ & $104(38.0)$ & I & I \\
\hline \multicolumn{5}{|l|}{ Home garden present } \\
\hline Yes & $49(39.2)$ & $76(60.8)$ & $2.06(1.33,3.19)$ & $2.34(1.39,3.94)^{*}$ \\
\hline No & $179(62.2)$ & $109(37.8)$ & I & I \\
\hline \multicolumn{5}{|l|}{ Mobile phone available } \\
\hline Yes & $142(49.8)$ & $143(50.2)$ & $2.06(1.33,3.19)$ & $2.83(1.62,4.92)^{*}$ \\
\hline No & $86(67.2)$ & $42(32.8)$ & I & 1 \\
\hline
\end{tabular}

Notes: ${ }^{*} p \leq 0.05 ;{ }^{* *} p>0.05$

Abbreviation: OR, odds ratio.

nutrition and health messages as a means of advocating. Having a bank account/savings is also significantly associated with dietary diversity. Pregnant women who had a bank/saving account were three times more likely
(95\% CI: $1.96,4.87)$ to have a diversified diet than those who do not. This is consistent with a study conducted in Limpopo Province, South Africa where households with low dietary diversity were also the most 
impoverished, and fewer households had money in a savings account, ${ }^{10}$ and scores for dietary diversity have been shown to be linked to socioeconomic characteristics. $^{20}$

This study has some limitations. Food availability in the household might vary with the seasons which affect dietary diversity and the assessment of dietary intake depends on the 24-hour recall method, which may not accurately reflect their past feeding experience. Moreover, the nature of this study was a cross-sectional design, which does not show the cause and effect relationship.

\section{Conclusions}

The measure using a 24-hour recall dietary diversity assessment indicated that inadequate dietary diversity among the pregnant women was high. In this study, factors such as availability of information from radio, having a protected water source, having a latrine, the availability of a home garden, being urban and having a mobile phone play a vital role in the achievement of the dietary diversity for pregnant women. These variables which had a significant association to dietary diversity were indicators of better living conditions. Therefore, attention should be paid to improve the better living condition of pregnant women by addressing the determinate variables through community awareness.

\section{Abbreviations list}

AOR, adjusted odd ratio; MUAC, mid-upper arm circumference.

\section{Availability of data and materials}

All the required data supporting the findings are incorporated within the manuscript.

\section{Acknowledgments}

Madda Walabu University provided funds to undertake this study and is acknowledged for the financial support. We thank the Bale Zone health office and public health facilities for their support. Finally, our appreciation also goes to the study participants.

\section{Author contributions}

Both authors contributed to conception, design, field study, data collection, analysis, and interpretation, writing of the manuscript, gave final approval of the version to be published, and agree to be accountable for all aspects of the work.

\section{Disclosure}

The authors report no conflicts of interest in this work.

\section{References}

1. Vakili M, Abedi P, Sharifi M, Hosseini M. Dietary diversity and its related factors among adolescents: a survey in Ahvaz-Iran. Glob $J$ Health Sci. 2013;5(2). doi:10.5539/gjhs.v5n2p181

2. Kennedy GL, Pedro MR, Seghieri C, Nantel G, Brouwer I. Dietary diversity score is a useful indicator of micronutrient intake in non-breast-feeding Filipino children. $J$ Nutr. 2007;137(2):472-477. doi:10.1093/jn/137.3.798S

3. FAO and FHI 360. Minimum Dietary Diversity for Women: A Guide for Measurement. Rome: FAO; 2016.

4. Daniels MC. Dietary Diversity as a Measure of the Micronutrient Adequacy of Women's Diets: Results from Metropolitan Cebu, Philippines Site. Washington, DC: Food and Nutrition Technical Assistance II Project; 2009.

5. Chakona G, Shackle ton C. Minimum dietary diversity scores for women indicate micronutrient adequacy and food insecurity status in South African towns. Nutrients. 2017;9:812. doi:10.3390/nu9080812

6. Lee SE, Talegawkar SA, Merialdi M, Caulfield LE. Dietary intakes of women during pregnancy in low- and middle-income countries. Public Health Nutr. 2013;16(8):1340-1353. doi:10.1017/ S1368980012004417

7. Leyna GH, Mmbaga EJ, Mnyika KS, Hussain A, Klepp K-I. Insecurity is associated with food consumption patterns and anthropometric measures but not serum micronutrient levels in adults in rural Tanzania. Public Health Nutr. 2010;13(9):1438-1444. doi:10.1017/S1368980009992163

8. UNICEF. Tracking Progress on Child and Maternal Nutrition: A Survival and Development Priority. New York: UNICEF; 2009.

9. Labadarios D, Steyn NP, Nel J. How diverse is the diet of adult South Africans? Nutr J. 2011;10(1). doi:10.1186/1475-2891-10-33

10. Drimie S, Faber M, Vearey J, Nunez L. Dietary diversity of formal and informal residents in Johannesburg, South Africa. BMC Public Health. 2013;13(1):911. doi:10.1186/1471-2458-13-911

11. Feed The Future. Feed the future handbook of indicator definitions [Internet]. Feed the Future. 2014

12. Arimond M, Wiesmann D, Becquey E, Carriquiry A, Daniels MC, Deitchler M. Simple food group diversity indicators predict micronutrient adequacy of women's diets in 5 diverse, resource-poor settings. J Nutr. 2010;140(11):2059S-2069S. doi:10.3945/jn.110.123414

13. Henjum S, Torheim LE, Thorne-Lyman AL, Chandyo R, Fawzi WW, Shrestha PS. Low dietary diversity and micronutrient adequacy among lactating women in a peri-urban area of Nepal. Public Health Nutr. 2015;18(17):3201-3210. doi:10.1017/S1368980015000671

14. Arsenault JE, Yakes EA, Islam MM, Hossain MB, Ahmed T, Hotz C. Very low adequacy of micronutrient intakes by young children and women in rural Bangladesh is primarily explained by low food intake and limited diversity. J Nutr. 2013;143(2):197-203. doi:10.3945/ jn.112.169524

15. Saaka M. Maternal dietary diversity and infant outcome of pregnant women in Northern Ghana. Int $J$ Child Health Nutr. 2013;1 (2):148-156.

16. World Health Organization: Good Maternal Nutrition. The Best Start in Life. WHO Regional Office for Europe (2016). Copenhagen Ø (Denmark): UN City; 2016.

17. Central Statistical Agency (CSA) [Ethiopia] and ICF. Ethiopia Demographic and Health Survey 2016. Addis Ababa (Ethiopia) and Rockville (MD): CSA and ICF; 2016. 
18. Arimond M, Ruel MT. Dietary diversity is associated with child nutritional status: evidence from 11 demographic and health surveys. J Nutr. 2004;134(10):2579-2585. doi:10.1093/jn/134.10.2579

19. Nguyen PH, Avula R, Ruel MT, Saha KK, Ali D, Tran LM. Maternal and child dietary diversity are associated in Bangladesh, Vietnam, and Ethiopia. $J$ Nutr. 2013;143(7):1176-1183. doi:10.3945/ jn. 112.172247

20. Savy M, Martin PY, Traissac P, Eymard DS, Delpeuch F. Dietary diversity scores and nutritional status of women change during the seasonal food shortage in rural Burkina Faso. J Nutr. 2006;136 (10):2625. doi:10.1093/jn/136.2.343

21. Government of the Federal Democratic Republic of Ethiopia. National Nutrition Programme. June 2013-June 2015. 2015.

22. Weldehaweria NB, Misgina KH, Weldu MG. Dietary diversity and related factors among lactating women visiting public health facilities in Aksum town, Tigray, Northern Ethiopia. BMC Nutr. 2016;2:38. doi:10.1186/s40795-016-0077-3

23. Central Statistical Agency [Ethiopia] and ICF International. Ethiopia Demographic and Health Survey 2011. Addis Ababa; Calverton, ML: Central Statistical Agency and ICF International; 2012.

24. Bale Zone Report. Socio Demographic and Socio Economic Profile of Bale Zone, Southeast Ethiopia. Bale Zone: CSA I; 2016.

25. Anne Swindale Paula Bilinsky. Household Dietary Diversity Score (HDDS) for Measurement of Household Food Access: indicator Guide VERSION. Washington (DC): FANTA FHI 360; 2006.

26. Kiboi W, Kimiywe J, Chege P. Determinants of dietary diversity among pregnant women in Laikipia County, Kenya: a cross-sectional study. BMC Nutr. 2017;3:12. doi:10.1186/s40795-017-0126-6

27. Nega G. Dietary diversity and associated factors among rural households in south Gondar zone, Northwest Ethiopia. November 2015.
28. Saaka M, Oladele J, Larbi A, Zeledon IH. Dietary diversity is not associated with hematological status of pregnant women resident in rural areas of Northern Ghana Hindawi Publishing Corporation. J Nutr Metab. 2016;2017(2):38. Article ID 8497892. doi:10.1186/ s40795-016-0077-3

29. Miura S, Kunii O, Wakai S. Home gardening in urban poor communities of the Philippines. Int J Food Sci Nutr. 2003;54(5):409. doi:10.1080/09637480310001622305

30. Ekesa BN, Blomme G, Garming H. Dietary diversity and nutritional status of pre-school children from Musa-dependent households in Gitega (Burundi) and Butembo (Democratic Republic of Congo). Afr J Food Agric Nutr Dev. 2011;11:4.

31. EFMH and UNICEF. Community based Nutrition 2013 Baseline Survey: Key Baseline Findings and Discussion on Results from the 2013 Baseline Surveys on 145 Newly Implementing. Ethiopian Federal Ministry of Health and Addis Ababa: UNICEF; 2013.

32. Ahmed FF, Naphtali J. Socioeconomic characteristics and food diversity amongst high income households: a case study of Maiduguri metropolis, Borno state, Nigeria. Am J Soc Mgm. Sci. 2014;5(1):19-26.

33. Mekuria G, Wubneh Y, Tewabe T. Household dietary diversity and associated factors among residents of Finote Selam town, North West Ethiopia: a cross sectional study was showed those positive relationships between using of protected water and consuming of diversified food. BMC Nutr. 2017;3:28. doi:10.1186/s40795-017-0148-0

34. Taruvinga A, Muchenje V, Mushunje A. Determinants of rural household dietary diversity: the case of Amatole and Nyandeni districts, South Africa. Int J Dev Sustain. 2013;2(4):2233-2247.
Nutrition and Dietary Supplements

\section{Publish your work in this journal}

Nutrition and Dietary Supplements is an international, peerreviewed, open access journal focusing on research into nutritional requirements in health and disease, impact on metabolism and the identification and optimal use of dietary strategies and supplements necessary for normal growth and development. The journal welcomes submitted papers covering original research, basic science, clinical \& epidemiological studies, reviews and evaluations, guidelines, expert opinion and commentary, case reports and extended reports. The manuscript management system is completely online and includes a very quick and fair peer-review system, which is all easy to use. Visit http://www.dovepress.com/testimonials.php to read real quotes from published authors. 